\title{
Correlation between the composition and the rate of ionic transport in perovskites
}

\section{David L. Fuks, Arnold E. Kiv}

Department of Materials Engineering, Ben-Gurion University of the Negev, P. O. Box 653 Beer-Sheva, 84105, Israel

*Corresponding author. Tel: (+972) 86461460; Fax: (+972) 6472946; E-mail: kiv@bgu.ac.il

Received: 01 October 2012, Revised: 02 December 2012 and Accepted: 04 December 2012

\section{ABSTRACT}

Practically applicable approach for the fabrication of $\mathrm{ABO}_{3}$ perovskites with high rates of ionic transport is developed. The ionic transport in perovskites with transition metals at $\mathrm{B}$ - site is considered in terms of the theory of coordination compounds. It is shown that the structure of these materials is sensitive to the values of the effective charge of the ions of transition metals $\left(Z^{*}\right)$ and to the electronegativity $(\chi)$ of the surrounding cations. The magnitudes of $Z^{*}$ and $\chi$ can be varied by choosing the appropriate elements at sites A and B to induce a distortion of the short range order. This leads to reduction of potential barriers for formation and migration of structural defects including oxygen vacancies. In typical perovskites a correlation between the rates of the ionic transport and the estimated values of $Z^{*}$ and $\chi$ is found. Copyright $@ 2013$ VBRI press.

Keywords: Perovskites; coordination compounds; ionic transport.

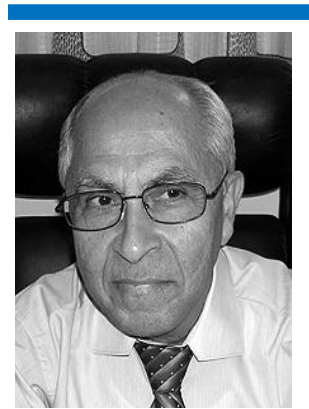

Arnold Kiv received the D. Sc. (Dr. Hab.) degree in solid state physics from Tartu Institute of Physics, Tartu, Estonia, in 1978. From 1964 to 1982 , he was a Senior Researcher and a Head of the Laboratory of Radiation Effects, Institute of Nuclear Physics, Academy of Sciences, Tashkent, Uzbekistan. From 1983 to 1998 , he was a Head of the Department of Theoretical Physics, SouthUkrainian National Pedagogical University, Odessa, Ukraine. In 1997, he was an Invited Professor, Western Ontario University, Canada. From 1999 to the present, he is a Professor-Researcher in the Department of Materials Engineering, Ben-Gurion University of the Negev, Israel. In 1996 and 2011 he was co-Director of NATO Advanced research Workshops and an Editor of two NATO Series books. He has about 200 publications, three monographs and three Invention Certificates in the field of radiation effects in solid state electronics. His research interests include mechanisms of formation of radiation defects in solids, interaction of fast particles with materials, radiation methods in microelectronics, including computer simulation, analytical calculations and experimental studies.

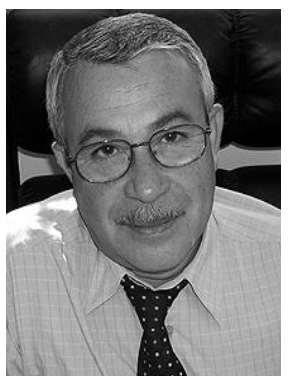

David Fuks received the Ph.D. degree in solid state physics from Tomsk State University, Tomsk, Russia, and the D.Sc. degree (Dr. Hab.) from Moscow State University, Moscow, Russia, in 1975 and 1984, respectively. In 1999, he was Invited Professor in the Institute of Physics, Federal University of Bahia, Bahia, Brazil, where he started his research on molecular dynamics simulations in solids. He was also Invited Professor in the Department of Metallurgy and Materials Science, Catholic University of Leuven, Leuven, Belgium, continuing this research. In 2000, he was Invited Professor in the Physics Department, Osnabrük University, Osnabrük, Germany where his research was devoted to the study of electronic properties of ferroelectrics. His main research interests concern quantummechanical theory of solids; thermodynamics and kinetics of phase transitions; diffusion in solids; molecular dynamics simulations, and computer modeling of processes of charge storage in dielectric media.

\section{Introduction}

The oxygen incorporation and migration in the perovskite cathode is an important stage of SOFC (solid oxide fuel cells) operation [1-3]. The simple perovskites did not allow achieving the desirable parameters of SOFC cathodes. Therefore nowadays the mixed perovskites are used. To fabricate the $\mathrm{ABO}_{3}$ mixed perovskites with necessary properties it is important to find the appropriate combinations of ions and also their fractional amounts at sites A and B. For this purpose the semi-empirical approaches based on concepts of Goldschmidt tolerance factor [4], critical radius and lattice free volume [5, 6], Pauling rules [7] and also the descriptor approach [10] are used. A lot of theoretical works are carried out to find a correlation between the atomic composition and physical properties of perovskites (see, for example, $[\mathbf{8 , 9}, \mathbf{9})$. Nevertheless the ways of purposeful varying the composition of perovskites to improve their characteristics in cathodes applications still remain unclear.

Last time the descriptor approach [10] is finding ever more wide application to improve the properties of perovskites and other materials. This approach consists in prediction of service parameters of materials by determination of correlations between calculated descriptors and measured material properties. Successful applications of 
the descriptor approach for improving the quality of metal ORR (oxygen reduction reaction) catalysts, activities of hydrogen oxidation, $\mathrm{CO}$ oxidation and oxygen surface exchange are demonstrated in [11-15]. The electronic structure descriptor for the ORR activity of electron-rich perovskites for their application in SOFC cathodes is described in [10]. This descriptor is the position of the oxygen $p$-band center calculated in perovskites with respect to Fermi energy. It was found that this theoretical descriptor correlates with the overall ORR activity. In above mentioned works $a b$ initio calculations were performed to get the theoretical descriptors.

In this sense the semi-empirical approaches (Goldschmidt tolerance factor, critical radius, lattice free volume, Pauling rules) present descriptors that do not demand time consuming $a b$ initio calculations for each specific composition of the mixed perovskite but operate with well tabulated data linked to the structure and the constituents of materials.

We applied the ideas of the theory of coordination compounds (TCC) to develop an approach for fabrication of perovskites with large rates of the ionic transport. The advantage of our approach is that the suggested descriptor can be obtained via simple and not time-consuming estimations based on well tabulated data. Our descriptor contains the parameters that are linked with the electronic structure of ions at A and B sites. It can be used as a predictive tool to regulate properties of perovskites by varying elements at both $\mathrm{A}$ and $\mathrm{B}$ sites.

\section{Experimental}

\section{TCC-based descriptor for improvement conducting properties of perovskites}

A considerable part of $\mathrm{ABO}_{3}$ perovskites contains transition metals (TM) at B-site inside polyhedrons that consist of oxygen ions and different types of cations. These structures could be studied using TCC approaches $[\mathbf{1 6}, \mathbf{1 7}]$. In [18] it is shown that on the basis of constructs of TCC a theoretical forecast for structural stability of different phases containing TM is possible. In this study we follow the methodological scheme that was used in [18].

In the framework of TCC, a stability of structures with TM inside atomic polyhedrons with some summary electronegativity depends on the parameter $\Delta$ that is determined by the degree of the degeneration of energy levels of $d$-electrons of TM atoms [17]. $\Delta$ characterizes a magnitude of splitting of degenerated $d$-levels and is influenced by the effective charge of TM ions and by the field of surrounding atoms or molecules (ligands). This parameter shows a stability of the structure: the larger the value $\Delta$, the more stable is the system with the given symmetry. It is important for our consideration that changes of $\Delta$ do not result by all means in changes of the thermodynamically stable structural phases, but cause a formation of small structural imperfections (SSI). SSI arises at initial stages of structural transformations and can be interpreted as a precursor stage forgoing the transition from one thermodynamic stable state to another. According to the definition, SSI corresponds to such changes of $\Delta$ that lead only to the destabilization of the local structure (distortion of a short range order). It is known that a structural disordering leads to significant (several orders of magnitude) increase of the rates of atomic transport in crystals. This result is obtained on the basis of the model of random probability distribution of energy barriers for diffusion and is confirmed experimentally [19]. The analogous result is obtained using the percolation theory [20]. Below we describe how to implement practically the limited distortion of a short range order through variation of $\Delta$. [17]:

The splitting parameter $\Delta$ can be estimated using Eq. (1)

$$
\Delta=\beta Q F,
$$

where $\beta$ is a coefficient depending on the crystal structure, $Q$ is proportional to the summary electronegativity [21] of surrounding atoms, $\chi$, and the function $F$ depends on the positions of atoms in the coordination polyhedrons.

The simplified form of the function $F$ for the atomic coordination possessing cubic symmetry can be expressed as [17]:

$$
F=\alpha\left[N /(\alpha R)^{5}-e^{-2 \alpha R} f(\alpha R)\right]
$$

where $R$ is the mean distance between TM ion and ions of the nearest coordination shells; $\alpha$ is proportional to Slater effective charge, $\mathrm{Z}^{*}$, for $d$-electrons in the TM atom, $N$ is a numerical parameter, $f(\alpha R)$ is a polynomial function. The function $F$ gradually increases with increasing $\alpha$. Thus it depends on $Z^{*}$ in the same manner. The magnitude of $Z^{*}$ can be estimated using semi-empirical Slater rules [22].

Analyzing Eq. (1) and (2) one can conclude that $\Delta$ is determined, in particular, by $Z^{*}$ for $d$-electrons in TM ions and by $\chi$ of surrounding atoms. For higher values $Z^{*}$ and $\chi$ the larger magnitudes of $\Delta$ are expected. Thus proceeding from TCC we can influence the perovskite structural changes through the splitting parameter $\Delta$ managing the values $Z^{*}$ and $\chi$ by changing the TM ions at the site $\mathrm{B}$ and cations at the site $\mathrm{A}$ in the mixed $\mathrm{ABO}_{3}$ perovskites. For combinations of elements 1 and 2 at site $\mathrm{A}$ or $\mathrm{B}$ the average values of $Z^{*}$ and $\chi$ were estimated in the form:

$$
\begin{aligned}
& \overline{Z^{*}}=c_{1} Z_{1}^{*}+\left(1-c_{1}\right) Z_{2}^{*} \\
& \bar{\chi}=c_{2} \chi_{1}+\left(1-c_{2}\right) \chi_{2}
\end{aligned}
$$

where $c_{1}$ and $\left(1-c_{1}\right)$ are the atomic fractions of the TM atoms 1 and 2 at site $\mathrm{B}$ and $c_{2}$ and $\left(1-c_{2}\right)$ are the atomic fractions of the cations 1 and 2 at site $\mathrm{A}$. To estimate $\chi$ we account two coordination shells. For cubic $\mathrm{ABO}_{3}$ perovskites the summary electronegativity was estimated as:

$$
\chi=6 \chi_{o}+8 \bar{\chi}
$$

where $\chi_{O}=3.44$ is the electronegativity of the oxygen atom [21].

Using available experimental and theoretical data for the ionic transport in some perovskites we analyzed the influence of parameters $Z^{*}$ and $\chi$ on their ionic conductivity, $\sigma_{i}$, and diffusion coefficients for oxygen 
vacancies, $D_{V}$. Since $\Delta$ becomes larger when each of parameters $Z^{*}$ or $\chi$ increases, we introduced a new parameter $\xi=Z^{*} \cdot \chi$ and found the correlations between the ionic transport rates $\left(\sigma_{\mathrm{i}}, D_{V}\right)$ and parameter $\xi$.

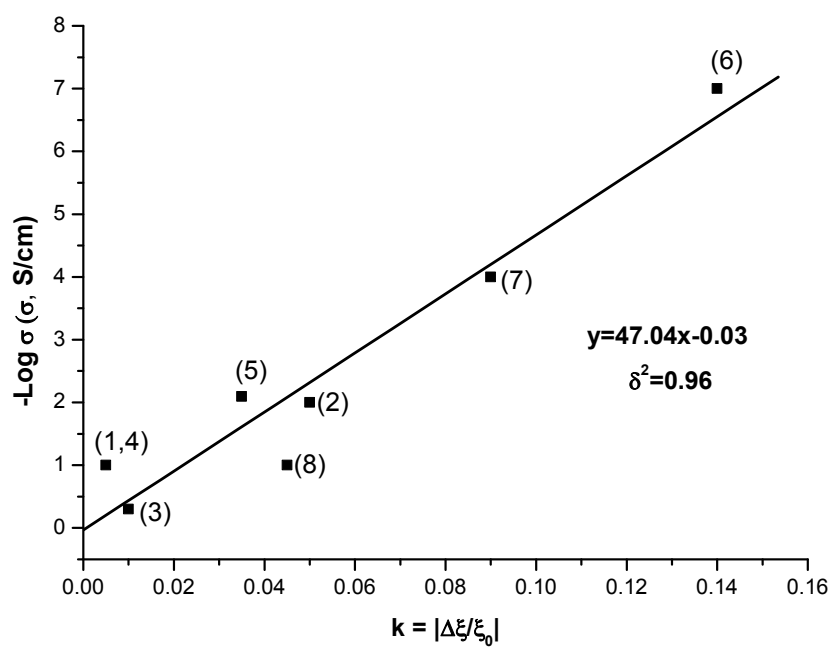

Fig. 1. Dependence of (- $\log \boldsymbol{\sigma})$ on $\boldsymbol{k}=\left|\Delta \xi / \xi_{0}\right|$. The numbers correspond to perovskites: $1 . \mathrm{Sr}\left(\mathrm{Co}_{07} \mathrm{Fe}_{03}\right) \mathrm{O}_{3-\delta}$ [23], 2. $\mathrm{La}\left(\mathrm{Co}_{08} \mathrm{Fe}_{02}\right) \mathrm{O}_{3-\delta} \delta$ [23], 3. $\left(\mathrm{La}_{08} \mathrm{Sr}_{02}\right)\left(\mathrm{Co}_{08} \mathrm{Fe}_{02}\right) \mathrm{O}_{3-\delta}$ [24], 4. $\left(\mathrm{La}_{05} \mathrm{Sr}_{05}\right)\left(\mathrm{Co}_{08} \mathrm{Fe}_{02}\right) \mathrm{O}_{3-\delta}$ [25, 26], 5. $\left(\mathrm{Pr}_{05} \mathrm{~Pb}_{05}\right) \mathrm{MnO}_{3-\delta}$ [27], 6. $\left(\mathrm{La}_{05} \mathrm{Sr}_{05}\right) \mathrm{MnO}_{3-\delta}$ [28, 29], 7. $\mathrm{Ca}\left(\mathrm{Ti}_{07} \mathrm{Al}_{03}\right) \mathrm{O}_{3-\delta}$ [30], 8. $\left(\mathrm{Bi}_{04} \mathrm{Sr}_{06}\right) \mathrm{FeO}_{3-\delta}[31]$.

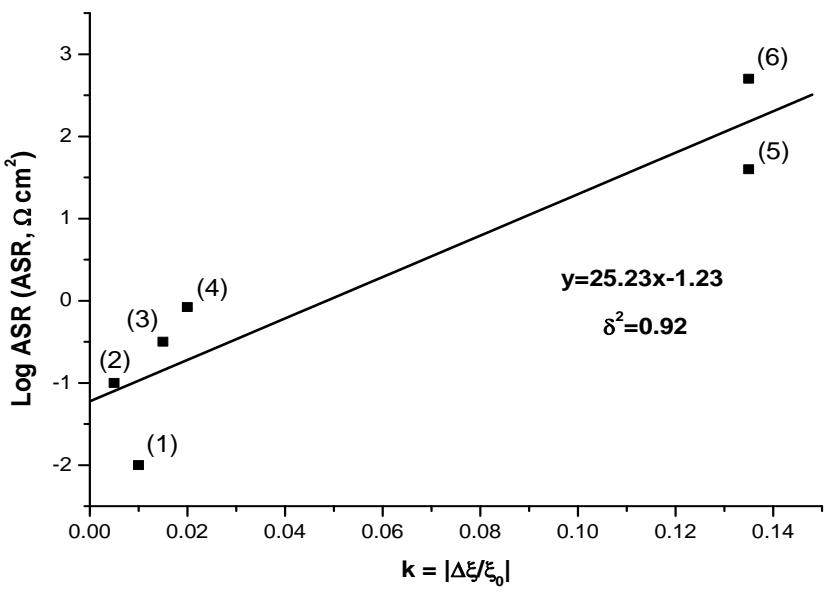

Fig. 2. Dependence of (- Log ASR) on $k=\left|\Delta \xi / \xi_{0}\right|$. The numbers correspond to perovskites: 1. $\quad\left(\mathrm{Ba}_{0.5} \mathrm{Sr}_{0.5}\right)\left(\mathrm{Co}_{0.75} \mathrm{Fe}_{0.25}\right) \mathrm{O}_{3}, \quad 2$. $\left(\mathrm{Sm}_{0.5} \mathrm{Sr}_{0.5}\right) \mathrm{CoO}_{3}$, 3. $\left(\mathrm{La}_{0.625} \mathrm{Sr}_{0.375}\right)\left(\mathrm{Co}_{0.25} \mathrm{Fe}_{0.75}\right) \mathrm{O}_{3}$, 4. $\left(\mathrm{La}_{0.75} \mathrm{Sr}_{0.25}\right) \mathrm{CoO}_{3}, 5$. $\left(\mathrm{La}_{0.75} \mathrm{Sr}_{0.25}\right) \mathrm{MnO}_{3}, 6 . \mathrm{LaMnO}_{3}$. The Area Specific Resistance (ASR) data are from $[\mathbf{1 0}]$.

\section{Results and discussion}

Starting with the assumption that the desirable ionic conductivity for SOFC cathodes is $10^{-1}-10^{-2} \mathrm{~S} / \mathrm{cm}$ at temperatures $400-800^{\circ} \mathrm{C}[\mathbf{1}]$, we found that for the considered group of perovskites the best values of $\sigma_{i}$, are obtained for the compounds with $\xi$ around 200.

It is known that a considerable improvement of the electrochemical performance was observed when $\mathrm{Mn}$ in LSM perovskites $\left(\mathrm{LaSrMnO}_{3}\right)$ was substituted partly or fully for $\mathrm{Fe}$ (LSF) [1]. Herewith $\xi$ changed from $\sim 175$ (LSM) to $\sim 194$ (LSF). For BSCF and LSCF perovskites
$\left(\mathrm{BaSrCoFeO}_{3}\right.$ and $\left.\mathrm{LaSrCoFeO}_{3}\right) \xi$ is equal to $\sim 194$ and $\sim 203$ consequently. The detailed statistical data for quantitative correlations between $\xi$ and the rates of ionic transport for some mixed perovskites are presented in Fig. 1-3. Fig. 1 displays the dependence between the ionic conductivity of perovskites listed in the caption and relative deviation, $\boldsymbol{k}$, of parameter $\xi$ from the value $\xi_{0}=200(\boldsymbol{k}$ $=\left|\Delta \xi / \xi_{0}\right|$ ). In Fig. 1, a strong tendency of the increase of ionic conductivity, when $\boldsymbol{k}$ decreases is seen. The complementary results are shown in Fig. 2 for the group of perovskites listed in the caption to this Figure. The correlation between diffusivities of oxygen vacancies and parameter $\boldsymbol{k}$ is shown in Fig. 3 for perovskites listed in the caption.

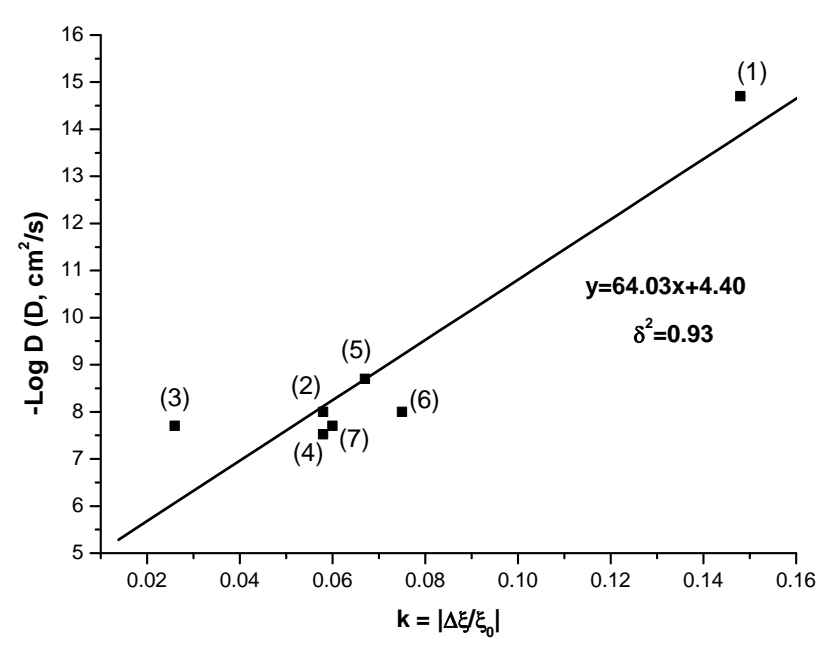

Fig. 3. Dependence of $(-\log \boldsymbol{D})$ on $\boldsymbol{k}=\left|\Delta \xi / \xi_{0}\right|$. The numbers correspond to perovskites: 1. $\left(\mathrm{La}_{05} \mathrm{Sr}_{05}\right) \mathrm{MnO}_{-\delta}$, 2. $\left(\mathrm{La}_{08} \mathrm{Sr}_{02}\right) \mathrm{CoO}_{3-\delta}$, 3. $\left(\mathrm{La}_{06} \mathrm{Ca}_{04}\right)\left(\mathrm{Co}_{08} \mathrm{Fe}_{02}\right) \mathrm{O}_{3-\delta}, \quad$ 4. $\left(\mathrm{La}_{06} \mathrm{Sr}_{04}\right)\left(\mathrm{Co}_{08} \mathrm{Ni}_{02}\right) \mathrm{O}_{3-\delta}$, 5. $\left(\mathrm{La}_{06} \mathrm{Sr}_{04}\right)\left(\mathrm{Co}_{06} \mathrm{Ni}_{04}\right) \mathrm{O}_{3-\delta}, \quad$ 6. $\quad\left(\mathrm{La}_{06} \mathrm{Sr}_{04}\right)\left(\mathrm{Co}_{04} \mathrm{Ni}_{06}\right) \mathrm{O}_{3-\delta}, \quad 7$. $\left(\mathrm{La}_{06} \mathrm{Ca}_{04}\right)\left(\mathrm{Fe}_{08} \mathrm{Co}_{02}\right) \mathrm{O}_{3-\delta}$. The data for diffusivities are from [32].

Note once more that the suggested criterion for the choice of composition of perovskites to improve their conductance properties is applicable to $\mathrm{ABO}_{3}$ perovskites with TM at site B. It should be applied together with existing approaches [4-7]. In many cases the adopted approaches are not effective enough, and our approach can play a decisive role. For example, authors of [3] estimated a tolerance factor for a set of perovskites. Analysis shows that in a lot of cases we do not get a correspondence of the tolerance factor to the perovskite quality, in particular for the conductance properties. For example, for the compound $\mathrm{La}_{0.4} \mathrm{Sr}_{0.6} \mathrm{MnO}_{3}$ the tolerance factor has a suitable value $\sim 1$, but service characteristics of this material are unsatisfactory. Indeed, in this case the introduced above parameter $\xi$ is equal 167 that should give low rates of ionic transport according to suggested $\xi$-criterion. Another compound $\mathrm{La}_{0.5} \mathrm{Sr}_{0.5} \mathrm{Co}_{0.5} \mathrm{Fe}_{0.5} \mathrm{O}_{3}$ is also characterized by the tolerance factor $\sim 1$ but has good conduction properties. In this case we obtained $\xi=200$ that is quite good according to $\xi$-criterion. It means that $\xi$-criterion indicates an optimal composition for considered group of perovskites and can serve as an additional useful approach to create new perovskites with improved conductance properties. 
Mechanisms of ionic transport in perovskites are intensively studied. Authors of a fundamental review [33] discussed in details the microscopic models for oxygen transport paths in perovskites including non-traditional compounds developed last time as SOFC cathodes and electrolyte materials. They underline the role of the modern approaches based on the computer modeling and simulations at the atomic level to create cathodes and electrolyte materials with improved conductance properties. Semiempirical approaches, however, in many cases determine the directions for creation of novel perovskite materials. Fig. 1-3 show that the ionic transport rates surely correlate with atomic characteristics $Z^{*}$ and $\chi$ through parameter $\xi$.

\section{Conclusion}

Correlations between the rates of the ionic transport in $\mathrm{ABO}_{3}$ mixed perovskites with TM at $\mathrm{B}$ site and atomic characteristics $\mathrm{Z}^{*}$ and $\chi$ of constituents at sites $\mathrm{A}$ and $\mathrm{B}$ are established. These correlations allow choosing combinations of ions at $\mathrm{A}$ and $\mathrm{B}$ sites that provide high rates of ionic transport in such perovskites. It means that $\xi$-criterion can serve as an additional useful approach to create new perovskites with improved conductance and diffusive properties.

\section{Acknowledgement \\ This work was supported by the GIF research Project\# 1-1025-5-10/2009.}

\section{Reference}

1. Pena, M. A.; Fierro, J. L. G. Chem. Rev. 2001, 101, 981. DOI: $10.1002 /$ chin. 200139260

2. Kammer Hansen, K.; Mogensen, M. ECS Transactions 2008, 13, 153.

DOI: $10.1149 / 1.3050387$

3. Richter, J. ; Holtappels, P.; N. Graul, T.; Nakamura, T.; Gauckler, L. J. Monatsh. Chem. 2009,140, 985.

PACS: 63.20.dk, 71.20.-b, 77.84.Bw, 31.15.V-, 61.72.-y

4. Müller, J.; Roy, R. The Major Ternary Structural Families; Springer-Verlag: New York, 1974, pp. 360 - 450. DOI: $10.1143 / \mathrm{JJAP} .40 .5999$

5. Shannon, R. D. Acta Crystallogr. Sect A 1976, 32, 751 . DOI: $10.1107 /$ S0567739476001551

6. Sammells, A. F.; Cook, R. L.; While, J. H.; Osborne, J. J.; Mac-Duff, R. C. Solid State Ionics 1992, 52, 111. DOI: $10.1039 / \mathrm{c} 2 \mathrm{cp} 40754 \mathrm{i}$

7. Pauling, L. J. Amer. Chem. Soc. 1927, 49, 765. DOI: $10.1063 / 1.1744099$

8. Fuks, D.; Dorfman, S.; Piskunov, S.; Kotomin, E. Phys. Rev. 2005, B 71, 014111-1-9. DOI: $10.1088 / 0953-8984 / 24 / 10 / 104024$

9. Fuks, D.; Bakaleinikov, L.; Kotomin, E.A.; Felsteiner, J.; Gordon, A.; Evarestov, R.A.; Gryaznov, D.; Maier, J. Solid State Ionics 2006, 177, 217

DOI: $10.1016 /$ j.ssi.2005.10.014

10. Lee, Y.-L.; Kleis, J.; Rossmeisl, J.; Shao-Horn, Y.; Morgan, D. Environ. Sci. 2011, 4, 3966. DOI: $10.1039 / \mathrm{C} 2 \mathrm{EE} 03397 \mathrm{~F}$

11. Norskov, J. K.; Rossmeisl, J.; Logadottir, A.; Lindqvist, L.; Kitchin, J. R.; Bligaard, T.; Jonsson, H. J. Phys. Chem. 2004, B 108, 17886. DOI: $10.1021 / \mathrm{jz} 300142 \mathrm{y}$

12. Stamenkovic, V. R.; Mun, B. S.; Arenz, M.; Mayrhofer, K. J. J.; Lucas, C. A.; Wang, G. F.; Ross, P. N. and Markovic, N. M. Nat. Mater. 2007, 6, 241 DOI: $10.1038 / \mathrm{nmat} 1840$

13. Zhang, J. L.; Vukmirovic, M. B.; Xu, Y.; Mavrikakis, M.; Adzic, R. R. Angew. Chem. Int. Ed. 2005, 44, 2132.

DOI: $10.1002 /$ anie.200462335
14. Greeley, J.; Stephens, I. E. L.; Bondarenko, A. S.; Johansson, T. P.; Hansen, H. A.; Jaramillo, T. F.; Rossmeisl, J.; Chorkendorff, I.; Norskov, J. K. Nat. Chem. 2009, 1, 552.

DOI: $10.1038 /$ nchem. 467

15. Bielanski, A.; Haber, J. Oxygen in catalysis, Marcel Dekker Inc.: New York 1991, pp. 350-450. DOI: $10.1103 /$ PhysRevLett.78.1500

16. Sugano, S.; Tanabe, Y.; Kamimura, H. Multiplets of Transition Metal ions in crystals, Academic Press: New York, London, 1970, pp. 110150. DOI: $10.1143 /$ JPSJ.40.723

17. Volkov, S. V.; Zasukha, V. A. Quantum Chemistry of Coordination Condensed Systems, Naukova Dumka: Kiev, 1985 (in Russian) pp.250280. DOI: $10.1016 / \mathrm{S} 0921-4526(01)$

18. Kiv, A. E.; Ezersky, V. I.; Talianker, M. M. Mater. Sci. Eng. 2003, A 352,100 . DOI: $10.1016 / \mathrm{S} 0921-5093(02) 00862-6$

19. Wilson, J. R.; Sase, M.; Kawada, T.; Adler, S. B. Electrochem Sol. St Lett. 2007, 10, B 81. DOI: $\underline{10.1149 / 1.2710178}$

20. Clementy, E.; Raimondi, D. L. J. Chem. Phys. 1963, 38, 2686. DOI: $\underline{10.1063 / 1.1725868}$

21. Avramov, I; Milchev, A. J. Non-Crystal. Sol. 1988, 104, 253 DOI: $10.10 .16 / 0022-3093(88) 90396-1$

22. Chen, Ying; Schuh, C. A. Acta Materialia 2006, 54, 4709. DOI: $10.1016 / j$.actamat.2006.06.011

23. Teraoka, Y.; Zhang, H. M.; Okamoto, K.; Yamazoe, N. Mater. Res. Bull. 1988, 23, 51 . DOI: $10.1016 / 0167-2738(91) 90034-9$

24. Sekido, S.; Tachibana, N.; Yamamura, Y.; Kambara, T. Solid State Ionics 1990, 37, 253. DOI: $10.1016 / 0167-2738(90) 90184-S$

25. Teraoka, Y.; Nobunaga, K.; Okamoto, K.; Yamazoe, N. Solid State Ionics 1991, 48, 207.

DOI: $\underline{10.1016 / 0167-2738(91) 90034-9}$

26. Kostogloidis, G. C.; Ftikos, C. Solid State Ionics 1999, 126, 143. DOI: $10.1016 / \mathrm{S} 0167-2738(99) 00230-1$

27. Kostogloidis, G. C.; Vasilakos, N.; Ftikos, C. J. Europe Ceram. Soc. 1997, 17, 1513 DOI: $10.1016 / \mathrm{S} 0955-2219(97) 00038-1$

28. Jiang, S. P. Solid State Ionics 2002, 146, 1 . DOI: $10.1016 / \mathrm{S} 0167-2738(01) 00997-3$

29. S. M. Haile, Acta Mater. 2003, 51, 5981 DOI: $10.1016 / j$.actamat.2003.08.004

30. Thangadurai, V.; Weppner, W. Ionics 2006, 12, 81. DOI: $10.1007 / \mathrm{s} 11581-006-0013-7$

31. Nui, Y.; Zhou, W.; Sunarso, J.; Ge, L.; Zhu, Z.; Shao, Z. J. Mater Chem. 2010, 20, 9619 .

DOI: $10.1039 / \mathrm{C} 0 \mathrm{JM} 02816 \mathrm{~A}$

32. Adler, S. B.; Lane J. A. and Steele, C. H. J. Electrochem Soc. 1996, $143,3554$. DOI: $10.1016 /$ j.jpowsour.2010.11.035

33. Chroneos, A.; Yildiz, B.; Tarancon, A.; Parfitta, D.; Kilner, J. A. Energy Environ. Sci. 2011, 4, 2774. DOI: $10.1039 / \mathrm{C} 1 \mathrm{EE} 02032 \mathrm{C}$

\section{Advanced Materials Letters}

Publish your article in this journal pubished quarterly. The journal is intended to provide top-quality peer-reviewed research papers in the fascinating field of materials
science particularly in the area of structure, synthesis and processing, characterization, advanced-state properties, and applications of materials. All articles are indexed on various databases including DOA and are avaliable for download for free. has fast and fair peer-review process. The journal includes communications. ADVANCED MATERIALS Letters is an international journa The manuscript management system is completely electronic and 